\title{
Pendampingan Pembuatan Hand Sanitizer Aroma Minyak Atsiri Sebagai Penunjang Pembelajaran Luring Di SMP Muhammadiyah 1 Prambanan
}

\author{
Wisnu Kundarto ${ }^{* 1}$, Dian Eka Ermawati ${ }^{1}$, Muhammad Fiqri Zulpadly ${ }^{1}$, Heru \\ Sasongko ${ }^{1}$, Sholichah Rohmani ${ }^{1}$, Anif Nur Artanti ${ }^{1}$, Daswati Rofiatun Sahifah ${ }^{2}$ \\ ${ }^{1}$ D3 Farmasi Sekolah Vokasi Universitas Sebelas Maret \\ ${ }^{2}$ SMP Muhammadiyah 1 Prambanan Yogyakarta \\ email: wisnukundarto.apt@gmail.com
}

\begin{abstract}
The schools have been allowed for doing face-to-face learning process with many requirements.Making own hand sanitizer will help schools to keep applying health protocol beside washing hands. Essential oils have been trusted for a long time give a calm effect and reduce stres. This activity have purpose to assistance hand sanitizer production with essential oils fragrance at SMP Muhammadiyah 1 Prambanan Yogyakarta. Knowledge have been transfered by team followed with demo and training to produce hand sanitizer with lemongrass fragrance at first activity. Knowledge score was determined from pre-test and post test answer score from multiple choice questions about hand sanitizer. Follow up became the next activity to ensure school can make their own hand sanitizer independently. The result showed knowledge score was increased from 52,11 to 92,11. School also have been made hand sanitizer independently with another essential oil varians. This products were limited used for school. Communication between team and school still continues.
\end{abstract}

Keywords: Hand sanitizer, essential oil, school, learning, face-to-face

\begin{abstract}
Abstrak
Pemerintah telah membolehkan sekolah-sekolah mengadakan proses pembelajaran luar jaringan (luring) atau tatap muka namun dengan banyak persyaratan. Pembuatan hand sanitizer secara mandiri akan sangat membantu sekolah untuk tetap menerapkan protokol kesehatan selain mencuci tangan. Minyak atsiri juga sudah telah lama dipercaya memberi efek tenang dan mengurangi stres. Pengabdian ini bertujuan untuk mendampingi pembuatan hand sanitizer aroma minyak atsiri di SMP Muhammadiyah 1 Prambanan Yogyakarta. Tim pada tahap pertama telah memberikan transfer ilmu disertai demo dan praktik pembuatan hand sanitizer aroma sereh. Peningkatan pengetahuan dilihat dari skor jawaban pre-test dan post-test dari pertanyaan pilihan ganda seputar hand sanitizer. Kegiatan tahap kedua adalah follow up kegiatan supaya sekolah mampu memproduksi hand sanitizer secara mandiri. Hasil skor pre-test dan post-test menunjukkan secara deskriptif terjadi peningkatan skor pengetahuan dari 52,11 menjadi 92,11. Sekolah juga telah mampu membuat hand sanitizer secara mandiri dengan beberapa varian minyak atsiri. Produk ini digunakan secara terbatas di lingkungan sekolah. Komunikasi dengan pihak sekolah masih dilakukan secara berkelanjutan.
\end{abstract}

Kata Kunci: Hand sanitizer, minyak atsiri, sekolah, pembelajaran, tatap muka

\section{PENDAHULUAN}

Pandemi COVID 19 memberi dampak sangat besar pada semua aspek, tak terkecuali pada asek pendidikan. Pendidikan harus tetap diselenggarakan untuk mencetak generasi penerus bangsa.
Masa normal baru disikapi pemerintah dengan mengeluarkan kebijakan terkait pembelajaran tatap muka [1]. Pemerintah Indonesia melalui Surat Keputusan Bersama 4 Menteri yaitu Menteri Pendidikan dan Kebudayaan, Menteri 
Dalam Negeri, Menteri Kesehatan, dan Menteri Agama, telah mengizinkan sekolah untuk melakukan pembelajaran tatap muka. Sekolah telah diperbolehkan menyelenggarakan pembelajaran tatap muka namun dengan aturan ketat [2]. Hand sanitizer sering menjadi alternatif pengganti cuci tangan dengan sabun dan air. Mencuci tangan dengan hand sanitizer dapat membantu menjaga kebersihan tangan agar terhindar dari penyakit [3]. Emosi negatif seperti bosan dapat saja berkembang pada masa normal baru akibat pandemi COVID 19 [4]. Aromaterapi dari minyak atsiri dapat digunakan sebagai alternatif untuk dapat merelaksasikan tubuh serta berperan dalam pengaturan emosional [5]. Berdasarkan latar belakang tersebut serta kesediaan sekolah sebagai mitra pengabdian, tim D3 Farmasi Sekolah Vokasi Universitas Sebelas Maret Surakarta mengadakan kegiatan pengabdian masyarakat berupa pendampingan pembuatan hand sanitizer dengan aroma minyak atsiri ke SMP Muhammadiyah 1 Prambanan Yogyakarta sebagai upaya penunjang penerapan protokol kesehatan di sekolah sekaligus memberikan kesan aromaterapi setelah penggunaan.

\section{METODE PENGABDIAN}

Metode yang digunakan dalam kegiatan pengabdian kepada masyarakat ini adalah transfer pengetahuan dan pendampingan pelatihan pembuatan hand sanitizer. Objek kegiatan ini adalah para guru SMP Muhammadiyah 1 Prambanan. Bahan yang digunakan dalam pembuatan hand sanitizer adalah alkohol 96\%, gliserol, hidrogen peroksida, akuades, dan sampel minyak atsiri. Alat yang digunakan adalah gelas ukur, batang pengaduk, dan gelas beker. Untuk melihat pengetahuan guru digunakan kuesioner dengan 10 pertanyaan berupa pilihan ganda dengan nilai jawaban benar adalah 10 poin per soal. Soal dibuat melalui Google form dan dibagikan melalui grup WhatsApp guru di
SMP ini pada tahap pre-test dan post-test. Pre-test dan post-test dilakukan pada hari yang sama yaitu sebelum kegiatan pelatihan dimulai dan setelah pelatihan selesai. Pengetahuan dilihat dari skor jawaban benar yang diperoleh pada saat pre-test dan post-test .Sosialisasi kegiatan kepada pihak sekolah dilakukan secara daring.

Adapun kegiatan yang telah dilakukan mencakup dua hal. Kegiatan pertama adalah pemberian informasi terkait produksi hand sanitizer dilanjutkan dengan demo pelatihan pembuatan hand sanitizer. Guru-guru dibagi dalam kelompok kecil dan didampingi oleh dosen. Bahan baku pembuatan sediaan hand sanitizer dan minyak atsiri pada kegiatan ini diberikan oleh tim pengabdian, sedangkan pihak sekolah membantu memfasilitasi tempat dan alatalat yang diperlukan. Informasi seputar hand sanitizer diberikan oleh tim pengabdian melalui ceramah dan leaflet. Paham tidaknya guru secara kualitatif dilihat dari keaktifan guru bertanya saat sesi diskusi, dan secara kuantitatif dievaluasi dari pencapaian skor nilai pretest dan post-test. Pertanyaan pada soal pretest dan post-test diambilkan dari materi penyuluhan. Analisa data dilakukan secara deskriptif untuk menggambarkan ada tidaknya kenaikan pengetahuan terkait hand sanitizer. Kegiatan kedua berupa pendampingan pembuatan hand sanitizer yang dilakukan pihak sekolah secara mandiri. Bahan dan alat untuk tahap ini sebagian besar diadakan oleh pihak sekolah, sedangkan tim pengabdian membantu dalam hal penyediaan minyak atsiri. Tim pengabdian mendampingi dan memberikan evaluasi terhadap produk yang dihasilkan. Kegiatan pertama dan kedua dilakukan dengan tetap mematuhi protokol kesehatan. 


\section{HASIL DAN PEMBAHASAN}

Kegiatan pengabdian yang telah dilakukan terdiri dari 2 tahap, yaitu pelatihan pembuatan hand sanitizer dan pendampingan pembuatan hand sanitizer secara mandiri.

\section{Pelatihan Pembuatan Hand Sanitizer}

Kegiatan tahap pertama ini dilakukan pada 5 Juni 2021. Tim pengabdian sebelum melakukan penyuluhan, terlebih dahulu membagikan soal pre-test melalui media Google Form dan disebarkan ke perwakilan pihak sekolah untuk dikerjakan oleh para guru. Tim pengabdian selanjutnya memberikan informasi seputar hand sanitizer melalui presentasi (Gambar 1) serta leaflet yang dibagikan. Leaflet berisi tentang formula dan cara pembuatan hand sanitizer mengacu pada formula standar World Health Organization (WHO) namun dengan modifikasi. Adapun perbedaan komposisi formula yang digunakan dapat dilihat pada Tabel 1 .

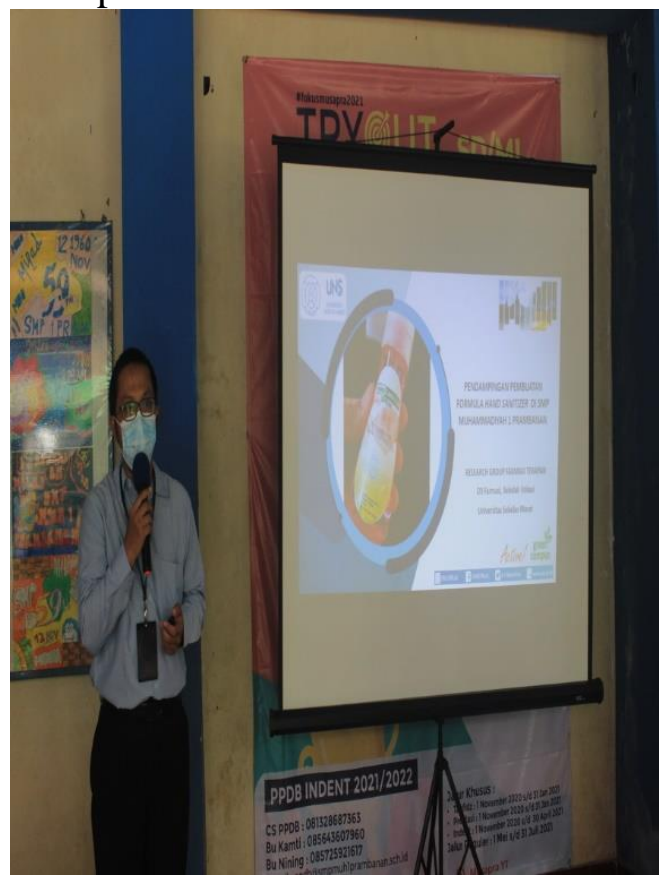

Gambar 1. Kegiatan ceramah materi penyuluhan

Tabel 1. Perbedaan komposisi formula hand sanitizer modifikasi dengan formula WHO
Nama
Formula hand
Formula
Bahan
sanitizer modifikasi

sanitizer

WHO *

\begin{tabular}{lcc}
\hline Etanol 96\% & $830 \mathrm{ml}$ & $833,33 \mathrm{ml}$ \\
\hline $\begin{array}{l}\text { Hidrogen } \\
\text { peroksida }\end{array}$ & $10 \mathrm{ml}$ & $41,7 \mathrm{ml}$ \\
$3 \%$ & &
\end{tabular}

$3 \%$

\begin{tabular}{lcc}
\hline Gliserol & $15 \mathrm{ml}$ & $14,5 \mathrm{ml}$ \\
\hline Minyak & $5 \mathrm{ml}$ &
\end{tabular}

sereh

\begin{tabular}{ccc}
\hline Akuades & $140 \mathrm{ml}$ ad $1000 \mathrm{ml}$ \\
\hline$*$ mengacu pada referensi [6]
\end{tabular}

Tim pengabdian selanjutnya melakukan demo pembuatan hand sanitizer dilanjutkan dengan diskusi (Gambar 2) . Guru-guru dibagi dalam 8 kelompok dan masing-masing didampingi oleh satu dosen (Gambar 3). Praktik pembuatan hand sanitizer dilakukan secara bergiliran untuk memastikan semua peserta paham cara pembuatan. Secara kualitatif, peserta juga aktif dalam bertanya pada saat sesi diskusi untuk memperjelas materi. Hasil kegiatan tahap pertama ini dapat dilihat pada Gambar 4.

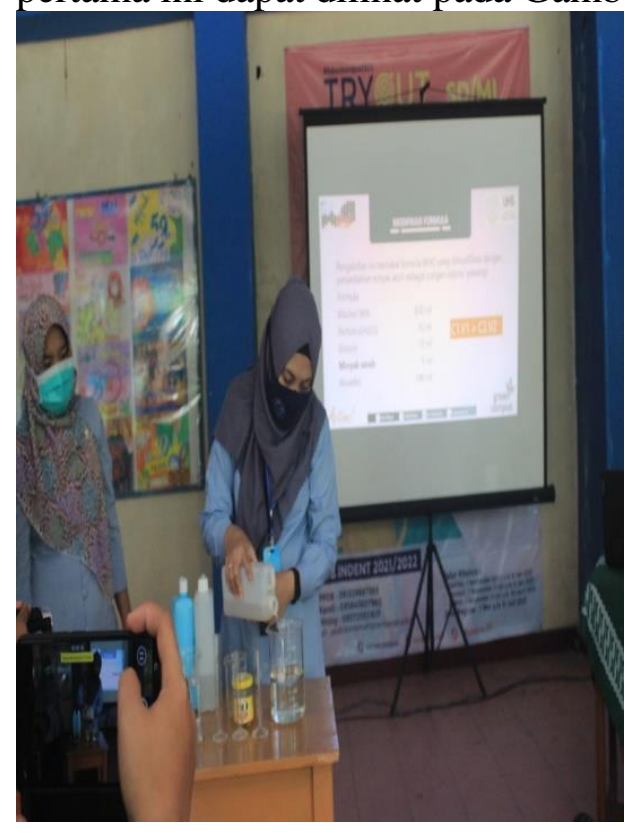

Gambar 2. Demo pembuatan hand sanitizer oleh tim pengabdian 


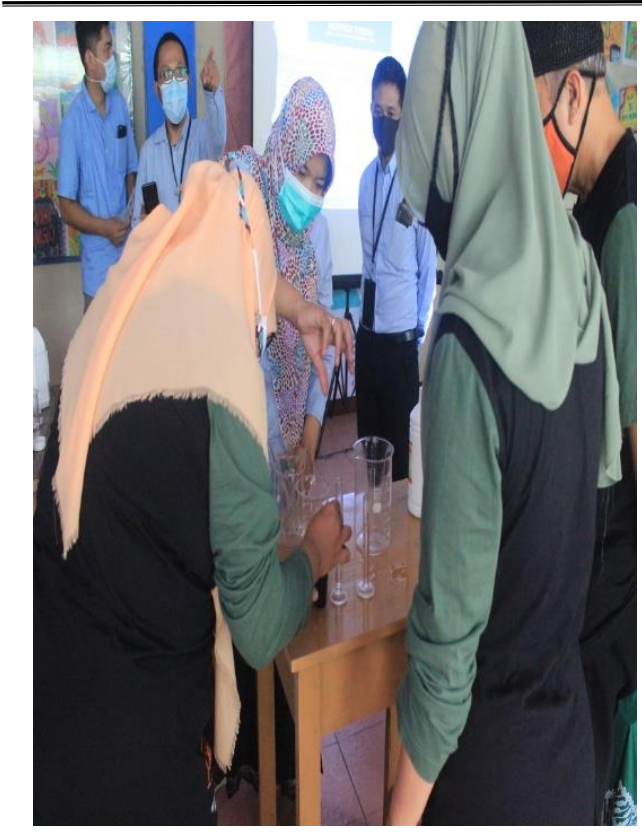

Gambar 3. Praktik pembuatan hand sanitizer didampingi tim pengabdian

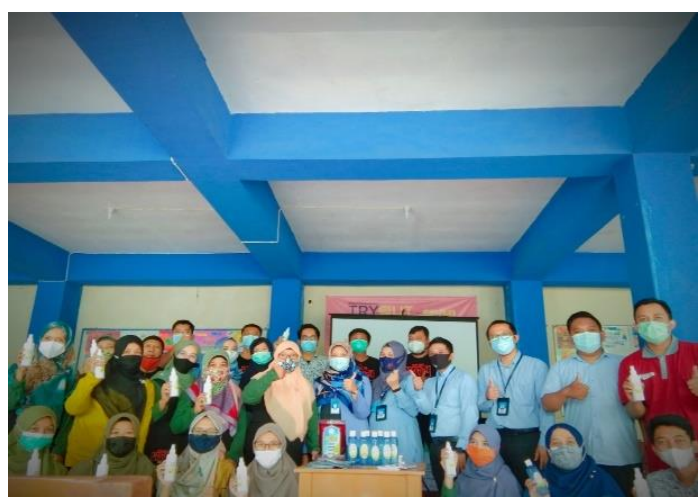

Gambar 4. Hasil pendampingan tahap pertama

Tim pengabdian selanjutnya memberikan post-test kepada peserta pengabdian untuk melihat pemahaman pengetahuan peserta seputar hand sanitizer. Adapun hasil skoring nilai pengetahuan dapat dilihat pada Tabel 2 .

Tabel 2. Hasil Skoring Nilai Pengetahuan Responden

$$
\text { (N=19) }
$$

\begin{tabular}{|cccccc|}
\hline No & $\begin{array}{c}\text { Inisial } \\
\text { Nama }\end{array}$ & L/P & $\begin{array}{c}\text { Pre } \\
\text { Test }\end{array}$ & $\begin{array}{c}\text { Post } \\
\text { Test }\end{array}$ & Keterangan \\
\hline 1. & EA & L & 60 & 90 & Naik \\
\hline 2 & S & P & 40 & 100 & Naik \\
\hline 3 & WP & P & 60 & 100 & Naik \\
\hline 4 & RTR & P & 40 & 100 & Naik \\
\hline 5 & RK & P & 60 & 100 & Naik \\
\hline 6 & RW & P & 50 & 100 & Naik \\
\hline 7 & BR & P & 50 & 100 & Naik \\
\hline 8 & SMW & P & 60 & 100 & Naik \\
\hline 9 & DAA & L & 30 & 70 & Naik \\
\hline 10 & IA & L & 60 & 100 & Naik \\
\hline 11 & NL & P & 70 & 90 & naik \\
\hline
\end{tabular}

\begin{tabular}{|c|c|c|c|c|c|}
\hline 12 & WIJ & $\mathrm{P}$ & 50 & 80 & naik \\
\hline 13 & $\mathrm{~N}$ & $\mathrm{P}$ & 60 & 80 & naik \\
\hline 14 & MBA & $\mathrm{L}$ & 70 & 100 & naik \\
\hline 15 & HS & $\mathrm{L}$ & 60 & 100 & naik \\
\hline 16 & GK & $\mathrm{L}$ & 20 & 100 & naik \\
\hline 17 & $\mathrm{AR}$ & $\mathrm{L}$ & 40 & 70 & naik \\
\hline 18 & EPF & $\mathrm{L}$ & 40 & 80 & naik \\
\hline 19 & DRS & $\mathrm{P}$ & 70 & 90 & naik \\
\hline \multicolumn{3}{|c|}{ Rata rata } & 52,11 & 92,11 & naik \\
\hline
\end{tabular}

Tabel 2 menunjukkan secara kuantitatif jika semua responden mengalami kenaikan skor saat post-test dibandingkan dengan pre-test, sehingga didapatkan rata-rata skor kenaikan pengetahuan adalah sebesar $40 \%$. Hasil ini dapat menggambarkan jika peserta guru sudah paham seputar hand sanitizer.

\section{Pendampingan Pembuatan Hand Sanitizer Secara Mandiri}

Tim pengabdian melakukan follow up kegiatan pada tanggal 19 Juni 2021. Kegiatan ini bertujuan supaya sekolah dapat melakukan produksi hand sanitizer secara mandiri. Tim juga mendampingi para guru melakukan produksi hand sanitizer seperti pada kegiatan tahap pertama. Hasil produk sekolah berupa produk hand sanitizer dengan aroma lavender (merk Surya) dapat dilihat pada Gambar 6.

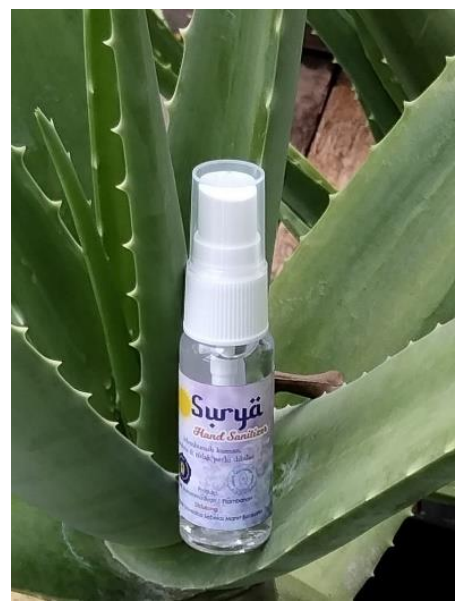

Gambar 6. Produk hand sanitizer aroma lavender buatan sekolah pada tahap kedua

Evaluasi kegiatan tahap kedua adalah sekolah sudah mampu melakukan produksi hand sanitizer secara mandiri, namun aroma minyak lavender yang dihasilkan pada produk ini kurang kuat. 
Solusi yang diberikan adalah penambahan jumlah minyak atsiri namun dengan mengurangi bagian air. Sekolah pada tahap selanjutnya merencanakan pembuatan produk hand sanitizer dengan varian aroma lain seperti rosemary, lime orange, peppermint, sweet orange, dan lemongrass. Secara umum sekolah sangat terbantu dengan kegiatan pengabdian ini. Produk yang dihasilkan akan digunakan secara terbatas di lingkungan sekolah. Produk dilabeli dengan komposisi zat aktif, cara pakai, peringatan, dan logo institusi. Diharapkan produk ini bermanfaat bagi pihak sekolah dalam menunjang aktivitas pembelajaran tatap muka dalam hal penerapan protokol kesehatan.

\section{SIMPULAN}

Kesimpulan kegiatan pengabdian masyarakat ini adalah pihak sekolah telah paham cara pembuatan hand sanitizer, serta telah berhasil membuat produk hand sanitizer dengan aroma minyak atsiri secara mandiri. Produk yang dihasilkan digunakan untuk kalangan terbatas di lingkungan sekolah. Produk ini juga hanya digunakan secara topikal dan tidak dimaksudkan untuk menggantikan cuci tangan sepenuhnya. Cuci tangan dengan sabun dan air mengalir tetap lebih diutamakan. Minyak atsiri yang ditambahkan selain sebagai corigen odoris, diharapkan mampu memberikan efek aromaterapi dan relaksasi bagi guru dan siswa sehingga lebih fokus dalam melakukan proses pembelajaran.

Penelitian membuktikan bahwa relaksasi dapat mengurangi kecemasan [7]. Tentunya aroma produk ini masih jauh lebih kecil jika dibandingkan dengan penggunaan diffuser dengan minyak atsiri murni. Penggunaan produk inipun difokuskan untuk membunuh kuman pada telapak tangan. Follow up kegiatan tetap akan dilakukan secara berkelanjutan melalui komunikasi secara daring supaya hasil kegiatan ini dapat bermanfaat seterusnya.

\section{UCAPAN TERIMAKASIH}

Ucapan terima kasih kepada Lembaga Penelitian dan Pengabdian Masyarakat Universitas Sebelas Maret yang telah mendanai pengabdian masyarakat ini melalui pendanaan bersumber dari dana non Anggaran Pendapatan dan Belanja Negara tahun 2021.

\section{DAFTAR PUSTAKA}

[1] R. Adawiyah, N.F. Isnaini, U. Hasanah, dan N. R. Faridah, Kesiapan Pelaksanaan Pembelajaran Tatap Muka pada Era New Normal di MI AtTanwir Bojonegoro, Jurnal Basicedu vol 5 no 5, 2021.

[2] M..N. Alyaa, Aturan Sekolah Tatap Muka di Wilayah PPKM Level 2 dan Level 3, Mulai dari Jarak Minimal Hingga Jumlah Murid, https://beritadiy.pikiranrakyat.com/pendidikan/pr702377335/aturan-sekolah-tatapmuka-di-wilayah-ppkm-level-2-danlevel-3-mulai-dari-jarak-minimalhingga-jumlah-murid, 2021.

[3] P. Srikartika, N. Suharti dan E, Anas. Kemampuan Daya Hambat Bahan Aktif Beberapa Merk Dagang Hand Sanitizer terhadap Pertumbuhan Staphylococcus aureus , Jurnal Kesehatan Andalas, vol 5 no 3. pp 16, 2016.

[4] S. Lenggogeni, Negative Emotions and Travel Desire: Exploration of the New Normal COVID-19 Stage in Indonesia, Jurnal Ipteks Terapan vol 15 no 2 pp 171-181.

[5] F. Pratiwi dan A. Subarnas, Review Artikel :Aromaterapi Sebagai Media Relaksasi, Farmaka, vol 18 no 3 pp 66-75, 2020.

[6] World Health Organization. Guide to Local Production: WHO-recomended 
Handrub Formulations

https://www.who.int/gpsc/5may/

Guide_to_Local_Production.pdf.

2010

[7] R. I. Matondang, Effects of Relaxation Therapy to Lower Anxiety, Jurnal Ipteks Terapan vol 14 no 2. 2020. 